Tropical Journal of Pharmaceutical Research September 2020; 19 (9): 1863-1869

ISSN: $1596-5996$ (print); 1596-9827 (electronic) (C) Pharmacotherapy Group, Faculty of Pharmacy, University of Benin, Benin City, 300001 Nigeria

\title{
2-Amino-nicotinamide induces apoptosis of prostate cancer cells via inhibition of PI3K/AKT and phosphorylation of STA3/JAK2
}

\author{
Junhui Ying*, Changchun Zhou, Yili Jin, Daqiao Lu, Bing Xiong, Jiahui Wei \\ Department of Urology Surgery, Dongyang People's Hospital Affiliated to Wenzhou Medical University, Dongyang, Zhejiang \\ 322100, China
}

*For correspondence: Email: JakobTapiaolc@yahoo.com; Tel: 0086-0578-86856101

Sent for review: 31 October 2019

Revised accepted: 27 August 2020

\begin{abstract}
Purpose: To study the cytotoxicity of 2-amino-nicotinamide against prostate cancer (PCa) cells, and the underlying molecular mechanism.

Methods: The effect of 2-amino-nicotinamide on cell viability and apoptosis was determined by 3-(4,5dimethylthiazol-2-yl)-2,5-diphenyltetrazolium (MTT) and flow cytometry, respectively, while its effect on cellular production of fluorescent-oxidized product from DCFH-DA was measured using flow cytometry. Apoptosis-related protein expressions were evaluated by western blot assay.

Results: 2-Amino-nicotinamide produced cytotoxicity against MCF-7, SGC7901, PCa $22 R v 1$ and $L N C a P$ cancer cell lines $(p<0.05)$. Mechanistic data revealed that 2-amino-nicotinamide activated apoptosis, and enhanced cleavage of PARP and caspase-3 in PCa 22Rv1 and LNCaP cells. In PCa $22 R v 1$ and $L N C a P$ cell lines, cytochrome $C$ and Bax levels were enhanced by treatment with 2-aminonicotinamide, while Bcl-2 protein level was suppressed $(p<0.05)$. Activated expressions of PI3K, Akt and ERK in PCa 22Rv1 and LNCaP cells were down-regulated, while p38 expression was increased. Moreover, 2-amino-nicotinamide suppressed the activation of JAK2 and STAT3, but did not alter total JAK2 and STAT3 levels in PCa 22Rv1 and LNCaP cells $(p<0.05)$.

Conclusion: 2-Amino-nicotinamide exerts cytotoxic effects on prostate carcinoma cells via activation of apoptosis and down-regulation of PI3KJAKT and STA3/JAK2. Thus, 2-amino nicotinamide is a potential bioactive agent for prostate cancer management.
\end{abstract}

Keywords: 2-Amino-nicotinamide, Apoptosis, Fluorescent-oxidized, Cytotoxicity

\begin{abstract}
This is an Open Access article that uses a fund-ing model which does not charge readers or their institutions for access and distributed under the terms of the Creative Commons Attribution License (http://creativecommons.org/licenses/by/4.0) and the Budapest Open Access Initiative (http://www.budapestopenaccessinitiative.org/read), which permit unrestricted use, distribution, and reproduction in any medium, provided the original work is properly credited.

Tropical Journal of Pharmaceutical Research is indexed by Science Citation Index (SciSearch), Scopus, International Pharmaceutical Abstract, Chemical Abstracts, Embase, Index Copernicus, EBSCO, African Index Medicus, JournalSeek, Journal Citation Reports/Science Edition, Directory of Open Access Journals (DOAJ), African Journal Online, Bioline International, Open-J-Gate and Pharmacy Abstracts
\end{abstract}

\section{INTRODUCTION}

Prostate cancer is one of the common malignancies diagnosed in the genitourinary system of men, and it the second highest cause of cancer-related deaths in men in US [1]. In prostate cancer patients, morbidity has been found to be related to family history, age factor and ethnicity [2]. The occurrence of prostate cancer and its progression are believed to involve interaction of genetic predisposition and environmental factors [3]. Susceptibility to prostate cancer is determined by genetic factors [3]. Analysis of the genomes of various ethnic 
groups globally has led to identification of more than 30 susceptible sites which may be linked to the risk of prostate cancer [3].

Studies on the role of genetic predisposition in prostate cancer have led to remarkable results [4]. The proliferation of prostate cancer is independent of androgens, with gradual progression resulting in the development of resistance to drugs and secondary endocrine therapy [5]. High levels of serum interleukin- 6 in prostate cancer cells lead to differentiation and transformation of malignant tumor cell to androgen-independent cells [6]. Interleukin-6 plays its role through various transducers and receptors such as p-Akt, p-ERK1/2 and Janus kinase (JAK). Moreover, signal transducer and activator of transcription (STAT) is used by interleukin-6 for transforming prostate cancer cells to androgen-independent form [6]. The main component which drives JAK/STAT pathway is p-STAT3. Many novel therapies have used JAK/STAT as the target for cancer treatment [7]. It has been reported that androgen receptor (AR) is activated by $\mathrm{PI} 3 \mathrm{~K}$ through interleukin-6, but the activation is not always dependent on PI3K pathway [8]. Apoptosis is stimulated by endogenous stress on cells [9]. The common stresses include aggregation of unfolded proteins in ER, calcium ion secretion from the ER and specific unprocessed proteins in the ER [9]. Apoptosis is generally induced by sustained stress in the endoplasmic reticulum [10]. The endoplasmic reticulum contains a member of pro-apoptotic protein family known as caspase-3 which is released during stress [11]. The present study was designed to investigate the cytotoxic effect of 2-aminonicotinamide on prostate cancer cells, and the molecular mechanism involved.

\section{EXPERIMENTAL}

\section{Drug and reagents}

Nicotinamide derivative (2-amino-nicotinamide) was provided by Alfa Aesar (Thermo Fisher Scientifics). Dimethyl sulfoxide (DMSO) and other reagents were obtained from SigmaAldrich.

\section{Cell culture}

The cancer cell lines MCF-7, SGC7901, PCa 22Rv1 and LNCaP were provided by the American Type Culture Collection (ATCC; Manassas, VA, USA). The cells were maintained in DMEM containing $10 \% \mathrm{FBS}$, under humid atmosphere containing $5 \% \mathrm{CO}_{2}$ at $37{ }^{\circ} \mathrm{C}$.

\section{MTT assay}

At $80 \%$ confluence, MCF-7, SGC7901, PCa 22Rv1 and LNCaP cancer cells were plated in 96-well plates, each at a density of $2 \times 10^{6}$ cells per well. The cells were incubated in DMEM containing $10 \%$ FBS for $24 \mathrm{~h}$, followed by replacement of the culture medium with fresh medium containing graded concentrations of 2amino nicotinamide i.e. 5, 10, 20, 40, 80, 160 and $320 \mu \mathrm{M}$ for $72 \mathrm{~h}$. At 24, 48 and $72 \mathrm{~h}$ of incubation, $25 \mu \mathrm{L}$ MTT solution was added to cells in each well, and incubation was continued for $4 \mathrm{~h}$. Then, the medium in each well was replaced with DMSO $(150 \mu \mathrm{l})$ to dissolve the solid formazan crystals formed. The optical density of each well was read at $568 \mathrm{~nm}$ in Varioskan Flash Multimode Reader.

\section{Apoptosis assay}

The PCa 22Rv1 and LNCaP carcinoma cells at $80 \%$ confluence were dispersed in glass cover slips of Lab-Tek Chamber Slides at a density of $2 \times 10^{6}$ cells per well. The cells were incubated with 2-amino nicotinamide at concentrations of 10, 20 and $40 \mu \mathrm{M}$ for $72 \mathrm{~h}$. Cells exposed to RQ1 RNase-Free DNase (one unit/100 $\mu \mathrm{L}$ ) served as control. Thereafter, the cells were fixed for $35 \mathrm{~min}$ in $4 \%$ paraformaldehyde, after which they were stained with fluorometric TUNEL system (Promega, Madison, WI, USA) in accordance with the manufacturer's procedure. The experiments were conducted in triplicate.

\section{Detection of ROS}

In PCa 22Rv1 and LNCaP cells $\left(2 \times 10^{5}\right.$ cells per well) exposed to 2-amino nicotinamide, ROS levels were determined using 2,7-dichlorofluorescein diacetate (DCFH-DA) stain. The cells were exposed 2-amino nicotinamide at doses of 10,20 and $40 \mu \mathrm{M}$ for $72 \mathrm{~h}$. Then, the cells were centrifuged, washed three times with PBS, and treated with $10 \mu \mathrm{M}$ DCFH-DA. After incubation under darkness for $20 \mathrm{~min}$, the cells were washed with PBS. Subsequently, fluorescent-oxidized product formed from DCFH-DA was monitored using flow cytometer (Beckman Coulter Inc.).

\section{Western blot assay}

In this assay, PCa 22Rv1 and LNCaP cells were treated for $72 \mathrm{~h}$ with 2-amino nicotinamide at doses of 10,20 and $40 \mu \mathrm{M}$ in 6-well plates, each cell line at a density of $2 \times 10^{6}$ cells per well. The cells were washed twice in cold PBS and subsequently lysed with ProteoJET cytoplasmic extraction kit (Fermentas; Thermo Fisher 
Scientific, Inc.). The protein contents of the lysates were determined using BCA Protein Assay kit (Thermo Fisher Scientific Inc.). Then, $30-\mu g$ protein samples were separated on $12 \%$ SDS-PAGE, followed by electrophoretic transfer to PVDF membranes. The membranes were blocked with $5 \%$ non-fat milk in TBST, prior to overnight incubation with primary antibodies at $4^{\circ} \mathrm{C}$. The antibodies used were anti-p-PI3 kinase, anti p-Akt, anti-JAK2, anti-p-Jak2, antip-ERK, anti-p38, anti-STAT3, anti-p-STAT3, anti-Bcl-2 and anti-Bax (Cell Signaling Technology, Inc. Danvers, MA, USA). Then, the membranes were rinsed with PBS, followed by incubation with horseradish peroxidaseconjugated rabbit secondary antibody for $1.5 \mathrm{~h}$ at room temperature. Enhanced chemiluminescence (ECL) development reagent was used for detection of the blots, while sodium Image Lab software (version 3.0; Bio-Rad Laboratories, Inc.) was used for blot analysis.

\section{RT-qPCR assay}

Total RNA was extracted from PCa 22Rv1 and LNCaP cells using TRIZOL reagent (Life Technologies; Thermo Fisher Scientific, Inc.) in line with the manual protocols. Then, $1 \mu \mathrm{g}$ RNA from each sample was reverse-transcribed to first-stand cDNA using the Super-Script First-Strand cDNA System (Invitrogen). Signal amplification was made using Platinum SYBR-Green qPCR Super Mix-UDG (Invitrogen). The master mix in each PCR reaction consisted of qPCR Super Mix-UDG, cDNA template, as well as forward and backward primers. The conditions used were: 15 min at $93{ }^{\circ} \mathrm{C}$, then 50 cycles at $93{ }^{\circ} \mathrm{C}$ for $25 \mathrm{sec}$, $58^{\circ} \mathrm{C}$ for $50 \mathrm{~min}$ and $70{ }^{\circ} \mathrm{C}$ for $25 \mathrm{sec}$. The relative gene expression levels were normalized to that of $\beta$-actin.

\section{Statistical analysis}

Data are presented as mean \pm standard deviation (SD) of triplicate values. Statistical analysis of data was made with SPSS version 17.0 software (SPSS Inc, Chicago, IL, USA). Data were compared using one-way analysis of variance, followed by Tukey's post-hoc test. Values of $p<0.05$ were taken as indicative of statistically significant differences.

\section{RESULTS}

\section{Cytotoxic effect of 2-amino nicotinamide on} lung, gastric and prostate cancer cells

As shown in Figure 1, 2-amino nicotinamide significantly and dose-dependently inhibited the growth of the tested cancer cells $(p<0.05)$. The half-maximal inhibitory concentration $\left(\mathrm{IC}_{50}\right)$ values of 2-amino nicotinamide for MCF-7, SGC7901, PCa 22Rv1 and LNCaP cells were $80,40,20$ and $20 \mu \mathrm{M}$, respectively. Thus, prostate carcinoma cells were more sensitive to 2-amino nicotinamide than lung and gastric cancer cells.

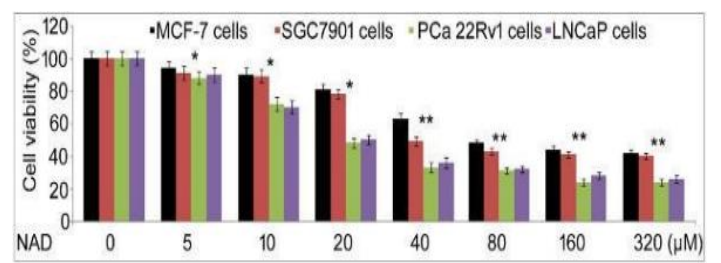

Figure 1: Effect of 2-amino nicotinamide on lung, gastric and prostate cancer cells. The MCF7, SGC7901, PCa 22Rv1 and LNCaP cells were exposed to 2-amino nicotinamide at doses of 5,10 , $20,40,80,160$ and $320 \mu \mathrm{M}$. Cell viability measurements were made using MTT assay at $72 \mathrm{~h}$ of incubation; ${ }^{*} p<0.05 ;{ }^{* *} p<0.02$, vs. control

\section{2-Amino nicotinamide inhibited viability of PCa 22Rv1 and LNCaP cells}

The inhibition of viabilities of PCa 22Rv1 and LNCaP cell by 2-amino nicotinamide was dependent on duration of treatment (Figure 2). The $\mathrm{IC}_{50}$ values of 2-amino nicotinamide for $\mathrm{PCa}$ $22 \mathrm{Rv} 1$ cells at 24,48 and $72 \mathrm{~h}$ were 80,40 and $20 \mu \mathrm{M}$, respectively. Treatment of LNCaP cells with 2-amino nicotinamide for 24, 48 and $72 \mathrm{~h}$ resulted in $\mathrm{IC}_{50}$ values of 160,40 and $20 \mu \mathrm{M}$, respectively. Therefore, in subsequent experiments, the cells were treated with 2-amino nicotinamide at doses of 10,20 and $40 \mu \mathrm{M}$ for $72 \mathrm{~h}$.

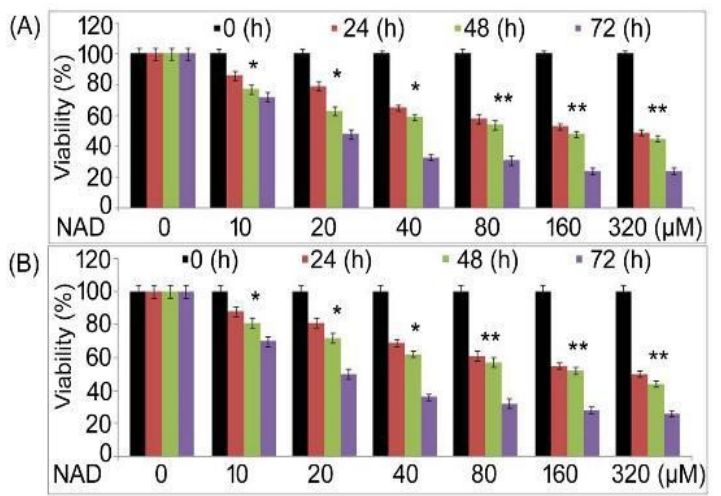

Figure 2: Effect of 2-amino nicotinamide on prostate cancer cells. PCa 22Rv1 cells (A) and LNCaP cells (B) were exposed to 2-amino nicotinamide at doses of $5,10,20,40,80,160$ and $320 \mu \mathrm{M}$ for 24,48 and $72 \mathrm{~h}$. Cell viability measurements were made using MTT assay. ${ }^{*} P<0.05$; ${ }^{* \star} p<0.02$, vs. control

Trop J Pharm Res, September 2020; 19(9): 1865 
2-Amino nicotinamide induced apoptosis in PCa 22Rv1 and LNCaP cells

Results from flow cytometry showed that exposure of PCa 22Rv1 cells to 2-amino nicotinamide at doses of 10,20 and $40 \mu \mathrm{M}$ resulted in 23.42, 53.67 and $93.82 \%$ apoptotic cells, respectively. In LNCaP cells exposed to 2amino nicotinamide at doses of 10,20 and 40 $\mu \mathrm{M}$ for $72 \mathrm{~h}$, the apoptotic cells were 19.67, 46.92 and $89.65 \%$, respectively.
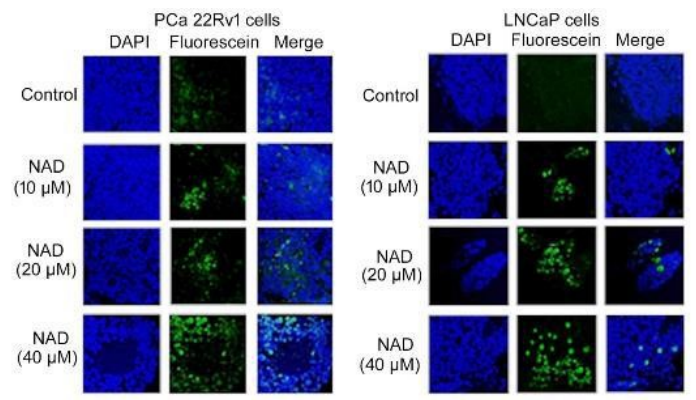

Figure 3: Effect of 2-amino nicotinamide on apoptosis of PCa 22Rv1 and LNCaP cells. The cells were exposed to 2-amino nicotinamide at doses of 10,20 and $40 \mu \mathrm{M}$, or DMSO, and were stained using TUNEL staining for flow cytometric analysis. ${ }^{*} P<0.05$; ${ }^{* *} p<$ 0.01 , vs. control

2-Amino nicotinamide enhanced cleavage of PARP and caspase-3 in PCa 22Rv1 and LNCaP cells

Treatment of PCa 22Rv1 and LNCaP cells with 2-amino nicotinamide at doses of 10, 20 and 40 $\mu \mathrm{M}$ promoted the cleavage of poly ADP-ribose (PARP) and caspase-3 (Figure 4).

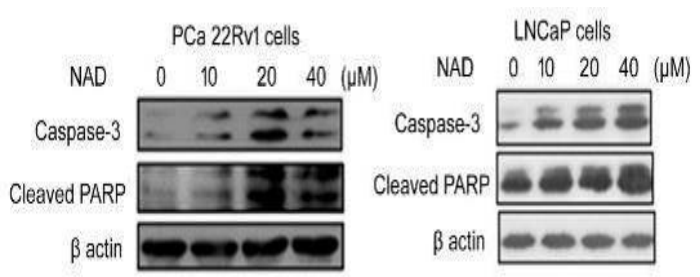

Figure 4: Effect of 2-amino nicotinamide on cleavage of PARP and caspase-3 in PCa 22Rv1 and LNCaP cells. (A) The cells were exposed to 2-amino nicotinamide at doses of 10,20 and $40 \mu \mathrm{M}$, or DMSO for $72 \mathrm{~h}$. Then, western blotting was used to determine the expressions of PARP and caspase- 3 , with $\beta$-actin as control

Nicotinamide derivative enhanced ROS generation in PCa 22Rv1 and LNCaP cells

Treatment of PCa 22Rv1 cells with 2-amino nicotinamide at doses of 10,20 and $40 \mu \mathrm{M}$ increased ROS levels to $41.64 \pm 3.21,68.75 \pm$
3.90 and $86.82 \pm 3.43 \%$, respectively, relative to $14.36 \pm 1.28 \%$ in untreated cells. The levels of ROS in LNCaP cells increased to $39.32 \pm$ $2.14,64.76 \pm 2.87$ and $84.98 \pm 3.93 \%$ on exposure to 2-amino nicotinamide at doses of 10,20 and $40 \mu \mathrm{M}$, respectively, relative to 13.56 $\pm 1.09 \%$ in control.

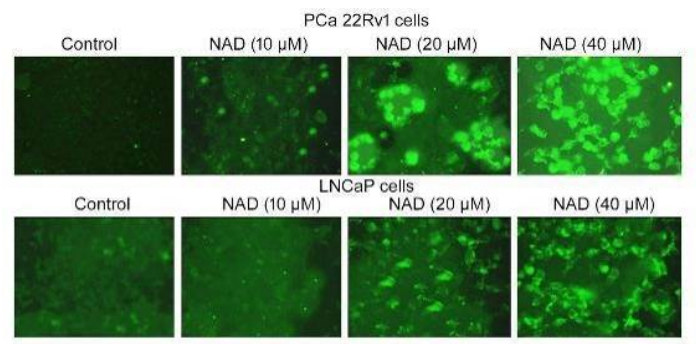

Figure 5: Effect of 2-amino nicotinamide on ROS production. $\mathrm{PCa} 22 \mathrm{Rv} 1$ and $\mathrm{LNCaP}$ cells were exposed to 2-amino nicotinamide at doses of 10, 20 and $40 \mu \mathrm{M}$ for $72 \mathrm{~h}$. The ROS generation was measured with flow cytometry after DCFH-DA staining

\section{2-Amino nicotinamide altered protein expressions in PCa 22Rv1 and LNCaP cells}

Western blotting was used to determine changes in cytochrome $\mathrm{c}$, Bax and $\mathrm{Bcl}-2$ due to treatment of $\mathrm{PCa} 22 \mathrm{Rv} 1$ and LNCaP cells with 2-amino nicotinamide for $72 \mathrm{~h}$. The treatment markedly promoted cytochrome $\mathrm{c}$ release into the cytoplasm in PCa 22Rv1 and LNCaP cells (Figure 6). The levels of Bax in PCa 22Rv1 and LNCaP cells were also increased on treatment with 2-amino nicotinamide at doses of 10, 20 and $40 \mu \mathrm{M}$. However, Bcl-2 expression was markedly decreased in these cells.

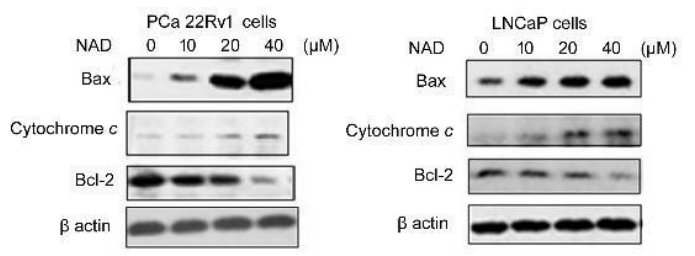

Figure 6: Effect of 2-amino nicotinamide on protein expressions of Bax, Bcl-2 and cytochrome c in $\mathrm{PCa}$ 22Rv1 and LNCaP cells exposed to 2-amino nicotinamide at doses of 10,20 and $40 \mu \mathrm{M}$ for $72 \mathrm{~h}$. The Bax, Bcl-2 and cytochrome $c$ levels were determined with western blotting, with $\beta$-actin as control

Nicotinamide derivative activated p38 and deactivated PI3K/Akt/ERK in PCa 22Rv1 and LNCaP cells

In PCa 22Rv1 and LNCaP cells, p38 expression was markedly and concentration-dependently elevated on exposure to 2-aminio nicotinamide 
at doses of 10, 20 and $40 \mu \mathrm{M}$ for $72 \mathrm{~h}$ (Figure 7). In contrast, the expressions of PI3K, Akt and ERK were significantly suppressed in $\mathrm{PCa}$ 22Rv1 and LNCaP cells by the same treatments.
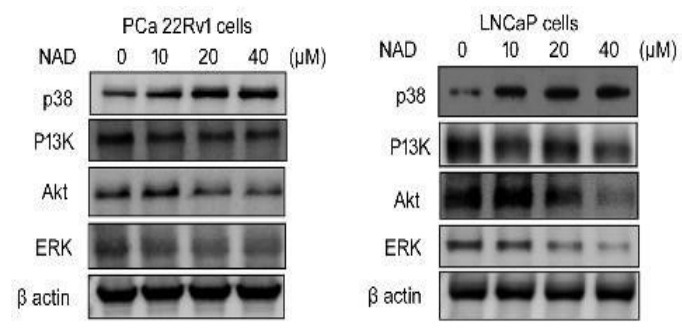

Figure 7: Effect of 2-amino nicotinamide on p38/PI3K/Akt/ERK. The expressions of activated p38, $\mathrm{PI} 3 \mathrm{~K}$, Akt and ERK were determined in PCa 22Rv1 and LNCaP cells using western blot assay, following treatment of the cells with 2-amino nicotinamide at doses of 10,20 and $40 \mu \mathrm{M}$ for $72 \mathrm{~h}$

\section{Nicotinamide derivative suppressed STAT3 phosphorylation in PCa 22Rv1 and LNCaP cells}

The expressions of JAK2 and STAT3 were reduced in $\mathrm{PCa} 22 \mathrm{Rv} 1$ and $\mathrm{LNCaP}$ cells on treatment with 2-amino nicotinamide at doses of 10, 20 and $40 \mu \mathrm{M}$ for $72 \mathrm{~h}$ (Figure 8). However, 2-amino nicotinamide had no effect on the expressions of total JAK2 and STAT3 in PCa 22Rv1 and LNCaP cells.

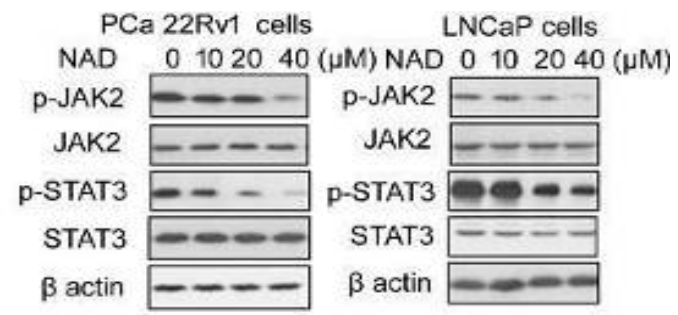

Figure 8: Effect of 2-amino nicotinamide on expressions of JAK2 and STAT3. The expression levels of JAK2, STAT3, p-JAK2 and p-STAT3 in PCa 22Rv1 and LNCaP cells exposed to 2-amino nicotinamide at doses of 10,20 and $40 \mu \mathrm{M}$ for $72 \mathrm{~h}$ were assayed with western blotting, with $\beta$-actin as internal control

\section{DISCUSSION}

Overproduction of ROS in carcinoma cells is involved in activation of cellular apoptosis via the mitochondrial pathway [12]. In many types of carcinoma cells (including prostate), ROS production results in the collapse of mitochondrial membrane potential and apoptosis [13]. In many cancer cells such as leukemia and melanoma, excessive generation of ROS and destabilization of mitochondrial membrane effectively induce apoptosis [14]. Reactive oxygen species (ROS) are considered to be indicators of cellular oxidative stress and initiators of apoptosis via the mitochondrial pathway [15]. The intrinsic apoptotic pathway is characterized by general collapse of MMP, followed by membrane permeabilization and subsequent pro-apoptotic protein release [16].

Many of the potent anti-cancer compounds such as betulinic acid and vitamin $E$ exhibit their effects by targeting the mitochondria, thereby increasing ROS levels [17]. In the current study, the cytotoxicity of 2-amino nicotinamide was initially determined against MCF-7 (lung), SGC7901 (gastric), and PCa 22Rv1 and LNCaP (prostate) cancer cell lines. The data clearly showed that 2-amino nicotinamide was cytotoxic against the four tested cancer cell lines, with maximum viability inhibitory effect against prostate cancers cells. The mechanism underlying the cytotoxicity of 2-amino nicotinamide was studied against PCa 22Rv1 and LNCaP carcinoma cells. TUNEL staining assay revealed that 2-amino nicotinamideinduced inhibition of the viabilities of PCa 22Rv1 and $\mathrm{LNCaP}$ cells was associated with activation of apoptosis. To confirm whether PCa 22Rv1 and LNCaP cell apoptosis was accompanied by overproduction of ROS, DCFH-DA stained cells were subjected to flow cytometry, and it was observed that exposure of PCa 22Rv1 and LNCaP cells to 2-amino nicotinamide resulted in excessive generation of ROS, when compared with control cells.

Moreover, 2-amino nicotinamide promoted the release of cytochrome $c$ into the cytosol, and increased levels of Bax in PCa 22Rv1 and LNCaP cells. In addition, it suppressed the levels of the anti-apoptotic factor, $\mathrm{Bcl}-2$ in $\mathrm{PCa}$ 22Rv1 and LNCaP cells. Thus, ROS overproduction was responsible for the cytotoxic potential of 2-amino nicotinamide against $\mathrm{PCa}$ 22Rv1 and LNCaP cells. This finding is consistent with previous reports. Cancer cell growth and apoptosis are regulated by the NF-KB pathway, and this has led to the identification of several functional components such as PI3K/Akt, ERK and p38 [18,19]. Suppression of activation of STAT3 and JAK2 through phosphorylation has been found to activate carcinoma cell apoptosis [20].

In the present study, 2-amino nicotinamide also targeted STAT3 and JAK2 activation in PCa 22Rv1 and LNCaP cells. There was increase in p38 expression, and suppression in expression levels of PI3K, Akt and ERK in PCa 22Rv1 and 
LNCaP cells treated with 2-amino nicotinamide. Studies have shown higher expression levels of STAT3 and Akt in carcinoma cells possessing anti-apoptotic potential [30]. Down-regulation of PI3K inhibits Akt which subsequently targets STAT3 [21]. Moreover, Akt down-regulation via suppression of JAK2 leads to inhibition of STAT3 [22]. The regulation of JAK2 is reduced on increasing Akt, which then reduces Akt and STAT3, indicating a negative feedback relationship [23]. In the present study, treatment of PCa 22Rv1 and LNCaP cells with 2-amino nicotinamide enhanced p38 expression and markedly inhibited activation of PI3K, Akt and ERK. In addition, JAK2 and STAT3 activation was also inhibited in PCa 22Rv1 and $\mathrm{LNCaP}$ cells by 2-amino nicotinamide.

\section{CONCLUSION}

These results indicate that 2-amino nicotinamide exhibits cytotoxic effect against prostate carcinoma cells via a mechanism involving apoptosis induction, up-regulation of ROS and up-regulation of the expressions of apoptotic factors. Moreover, 2-amino nicotinamide suppresses the activation of PI3K/AKT and STA3/JAK2 pathway. Therefore, 2-amino nicotinamide is a potential drug for the treatment of prostate cancer.

\section{DECLARATIONS}

\section{Conflict of interest}

No conflict of interest is associated with this work.

\section{Contribution of authors}

We declare that this work was done by the authors named in this article and all liabilities pertaining to claims relating to the content of this article will be borne by the authors. Junhui Ying designed the study and wrote the paper. Changchun Zhou, Yili Jin, Daqiao Lu, Bing Xiong and Jiahui Wei performed the experimental work. Changchun Zhou and Yili Jin carried out the literature study and compiled the data. Daqiao Lu, Bing Xiong and Jiahui Wei performed literature survey, analyzed the data and compiled the data. The research article was thoroughly read by all the authors before communication for the consideration of publication.

\section{Open Access}

This is an Open Access article that uses a funding model which does not charge readers or their institutions for access and distributed under the terms of the Creative Commons Attribution License (http://creativecommons.org/licenses/by/ 4.0) and the Budapest Open Access Initiative (http://www.budapestopenaccessinitiative.org/rea d), which permit unrestricted use, distribution, and reproduction in any medium, provided the original work is properly credited.

\section{REFERENCES}

1. D'Amico AV, Chen $M H$, Renshaw A, Loffredo $M$, Kantoff $P W$. Long-term follow-up of a randomized trial of radiation with or without androgen deprivation therapy for localized prostate cancer. JAMA 2015; 314: 12911293.

2. Fedorov A, Fluckiger J, Ayers GD, Li X, Gupta SN, Tempany C, Mulkern R, Yankeelov TE, Fennessy FM. A comparison of two methods for estimating DCE-MRI parameters via individual and cohort-based AIFs in prostate cancer: A step towards practical implementation. Magn Reson Imaging 2014; 32: 321 329.

3. Yu EY, Massard C, Gross ME, Carducci MA, Culine S, Hudes G, Posadas EM, Sternberg CN, Wilding G, Trudel GC, et al. Once-daily dasatinib: Expansion of phase II study evaluating safety and efficacy of dasatinib in patients with metastatic castration-resistant prostate cancer. Urol 2011; 77: 1166-1171.

4. Thomas $R$, Williams $M$, Sharma $H$, Chaudry A, Bellamy $P$. A double-blind, placebo-controlled randomised trial evaluating the effect of a polyphenol-rich whole food supplement on PSA progression in men with prostate cancer-the U.K. NCRN Pomi-T study. Prostate Cancer Prostatic Dis 2014; 17: 180-186.

5. Pedraza-Arevalo S, Hormaechea-Agulla D, Gomez-Gomez E, Requena MJ, Selth LA, Gahete MD, Castaño JP, Luque RM. Somatostatin receptor subtype 1 as a potential diagnostic marker and therapeutic target in prostate cancer. Prostate 2017; 77: 1499-1511.

6. Luo $C$, Zhang $H$. The role of proinflammatory pathways in the pathogenesis of colitis-associated colorectal cancer. Mediators Inflamm 2017: 2017; 5126048.

7. Han IH, Kim JH, Kim SS, Ahn MH, Ryu JS. Signalling pathways associated with IL-6 production and epithelial-mesenchymal transition induction in prostate epithelial cells stimulated with Trichomonas vaginalis. Parasite Immunol 2016; 38: 678-687.

8. Yang L, Wang L, Lin HK, Kan PY, Xie S, Tsai MY, Wang $\mathrm{PH}$, Chen YT, Chang C. Interleukin-6 differentially regulates androgen receptor transactivation via PI3K-Akt, STAT3, and MAPK, three distinct signal pathways in prostate cancer cells. Biochem Biophys Res Commun 2003; 305: 462-469.

9. Obakan P, Arisan ED, Coker-Gurkan A, Palavan-Unsal N. Epibrassinolide-induced apoptosis regardless of $p 53$ expression via activating polyamine catabolic machinery, a common target for androgen sensitive and

Trop J Pharm Res, September 2020; 19(9): 1868 
insensitive prostate cancer cells. Prostate 2014; 74: 1622-1633.

10. Reshma RS, Sreelatha KH, Somasundaram V, Satheesh Kumar S, Nadhan R, Nair RS, Srinivas P. Plumbagin, a naphthaquinone derivative induces apoptosis in BRCA 1/2 defective castrate resistant prostate cancer cells as well as prostate cancer stem-like cells. Pharmacol Res 2016; 105: 134-145.

11. Kwegyir-Afful AK, Ramalingam S, Purushottamachar $P$, Ramamurthy VP, Njar VC. Galeterone and VNPT55 induce proteasomal degradation of AR/AR-V7, induce significant apoptosis via cytochrome $c$ release and suppress growth of castration resistant prostate cancer xenografts in vivo. Oncotarget 2015; 6: 27440-27460.

12. Kim KY, Park KI, Kim SH, Yu SN, Park SG, Kim YW, Seo YK, Ma JY, Ahn SC. Inhibition of autophagy promotes salinomycin-induced apoptosis via reactive oxygen species-mediated PI3K/AKT/mTOR and ERK/p38 MAPK-dependent signaling in human prostate cancer cells. Int J Mol Sci 2017; 18: E1088.

13. Changou $C A$, Chen $Y R$, Xing L, Yen $Y$, Chuang $F Y$, Cheng RH, Bold RJ, Ann DK, Kung HJ. Arginine starvation-associated atypical cellular death involves mitochondrial dysfunction, nuclear DNA leakage, and chromatin autophagy. Proc Natl Acad Sci USA 2014; 111: 14147-14152.

14. Siedlakowski P, McLachlan-Burgess A, Griffin C, Tirumalai SS, McNulty J, Pandey S. Synergy of pancratistatin and tamoxifen on breast cancer cells in inducing apoptosis by targeting mitochondria. Cancer Biol Ther 2007; 7: 376-384.

15. Valko M, Leibfritz D, Moncol J, Cronin MT, Mazur M, Telser J. Free radicals and antioxidants in normal physiological functions and human disease. Int $\mathrm{J}$ Biochem Cell Biol 2007; 39: 44-84.

16. Ralph SJ, Rodríguez-Enríquez S, Neuzil J, MorenoSánchez R. Bioenergetic pathways in tumor mitochondria as targets for cancer therapy and the importance of the ROS-induced apoptotic trigger. Mol Aspects Med 2010; 31: 29-59.

17. Fulda S, Galluzzi L, Kroemer G. Targeting mitochondria for cancer therapy. Nat Rev Drug Discov 2010; 9: 447464.

18. Dilly AK, Ekambaram P, Guo Y, Cai Y, Tucker SC, Fridman $R$, Kandouz $M$, Honn KV. Platelet-type 12-lipoxygenase induces MMP9 expression and cellular invasion via activation of PI3K/Akt/NF-KB. Int J Cancer 2013; 133: 1784-1791.

19. He Y, Huang H, Farischon C, Li D, Du Z, Zhang K, Zheng $X$, Goodin S. Combined effects of atorvastatin and aspirin on growth and apoptosis in human prostate cancer cells. Oncol Rep 2017; 37: 953-960.

20. Abedinpour P, Baron VT, Chrastina A, Rondeau G, Pelayo J, Welsh J, Borgström P. Plumbagin improves the efficacy of androgen deprivation therapy in prostate cancer: A pre-clinical study. Prostate 2017; 77: 1550-1562.

21. Li Y, Zhu W, Tao J, Xin P, Liu M, Li J, Wei M. Fasudil protects the heart against ischemia-reperfusion injury by attenuating endoplasmic reticulum stress and modulating SERCA activity: The differential role for PI3KJAKt and JAK2/STAT3 signaling pathways. PLOS One 2012; 7: e48115.

22. Shanmugam MK, Rajendran $P$, Li F, Nema $T$, Vali $S$, Abbasi T, Kapoor S, Sharma A, Kumar AP, Ho PC, et al. Ursolic acid inhibits multiple cell survival pathways leading to suppression of growth of prostate cancer xenograft in nude mice. J Mol Med 2011; 89: 713-727.

23. Ma M, Ma Y, Zhang GJ, Liao R, Jiang XF, Yan XX, Bie FJ, Li XB, LV YH. Eugenol alleviated breast precancerous lesions through HER2/PI3K-AKT pathway-induced cell apoptosis and S-phase arrest. Oncotarget 2017; 8: 56296-56310. 